\title{
Return to sport
}

\author{
Roland Thomeé $\cdot$ Suzanne Werner
}

Received: 1 September 2011 / Accepted: 2 September 2011/Published online: 15 September 2011

(C) Springer-Verlag 2011

"When can I start playing again?" is one of the first questions an injured athlete asks the clinician. The higher the level of sports, the more anxious the athlete is to get back to sport after injury. Who can and who should answer this question? This is, of course, a multifactorial issue and should depend on factors such as the athlete's health status, type of injury, type and level of sport, as well as evidencebased injury risk factors for the healing tissue. In their decision-based return to play model comprising three steps, Creighton and co-workers [5] suggest that factors such as season, internal and external pressure to participate as well as conflict of interest should also be taken into account when drawing up guidelines for returning to sport after injury.

\section{Successful and safe return to sport}

Is it worth if an early return to sports is first rewarded by, for example, winning an important game or competition (i.e. a successful return) and is then followed by a re-injury in the next game or competition? Perhaps, if it means winning an Olympic gold medal, but not if it involves winning a lower division soccer game. This is naturally a moral dilemma

\footnotetext{
R. Thomeé $(\square)$

Department of Orthopaedics, Lundberg Laboratory for Orthopaedic Research, Sahlgrenska University Hospital, Göteborg University, SE-413 45 Göteborg, Sweden e-mail: roland.thomee@orthop.gu.se
}

\section{S. Werner}

Stockholm Sports Trauma Research Center, Department of Molecular Medicine and Surgery, Karolinska Institute, Stockholm, Sweden for the injured athlete, the coach, responsible members of the club/team and the team doctor and physiotherapist. In the literature, we can read about successful and/or safe return to sport. However, there are seldom any definitions of what the different authors mean by "successful" and "safe". Is a successful return to sport the same as a safe return? Thus, these two expressions, successful and safe, need to be clarified and better described in order to create evidence-based guidelines for returning to sport after injury.

\section{Injury severity}

It seems obvious that a severe injury requires more time to heal than a minor injury, and a prolonged period before returning to sport should therefore be considered. However, it is often difficult to decide on the severity of an injury. Within the area of sports medicine, injury severity is often defined as absence (number of days) from sport [6]. As discussed above, this definition can be hazardous, if we do not have strict criteria for deciding when an athlete is mentally and physically ready for a safe return. It seems reasonable that a more severe injury will prevent the athlete from making an early return to sport, since the healing of the injured tissue is more time-consuming, but also because regaining muscle strength, for instance, takes a considerable time [14]. This also means that the longer the healing time, the more time is needed for the gradual rebuilding of physical condition.

\section{Level of sport}

Furthermore, a return to sport depends on the level of sport, type of sport (e.g. pivoting vs. non-pivoting) and competitive 
versus recreational sporting activities. Greater demands are usually imposed on the injured athlete if he or she participates at a high level of sport rather than a lower level. These factors need to be taken into consideration before an athlete should be recommended to return to sport.

\section{Evaluation}

What criteria and evaluation tools should be used when determining whether or not the injured athlete is ready to return to sport? In general, measurements of muscle strength and range of motion, as well as different functional performance tests, are used. In a recent review and meta-analysis representing 5,770 athletes after anterior cruciate ligament (ACL) reconstruction, Ardern and coworkers [3] found that patients with good hop performance were more likely to return successfully to sport than patients with poor hop performance.

Based on a study of patients 11 months after anterior cruciate ligament reconstruction, Augustsson and coworkers [4] confirmed the importance of performing hop tests during both non-fatigued and fatigued conditions. The side-to-side difference between legs was considerably higher during fatigued conditions, indicating a need for more demanding tests to be able to decide whether or not the injured athlete should be allowed to go back to sport. In addition, a battery of muscle strength tests as well as a battery of functional performance tests have been found to be reliable and superior to a single strength or functional performance test when it comes to discriminating between the injured and non-injured side in patients with an ACL injury or after ACL reconstruction [7, 8]. However, there is a particular need to study the validity of different muscle function tests in terms of revealing whether an injured athlete, irrespective of the type of injury, can be recommended to return to sport. A number of investigations on patients report poor results for knee function after ACL reconstruction, despite a muscle function capacity of $\geq 90^{\circ}$ in their injured leg compared with their non-injured leg $[1,2,9-11]$.

\section{Limb symmetry index for muscle function}

The limb symmetry index (LSI) has been suggested as a criterion for normal and abnormal performance during different muscle function tests [12]. However, there is no consensus about the side-to-side difference that can be accepted before allowing an athlete to return to sport. A side-to-side difference of $90 \%$ has generally been used as an accepted measurement in the literature, but evidencebased studies to support this are lacking. Based on the result of a recent article on return to sports for patients who have undergone ACL reconstruction, the European Board of Sports Rehabilitation recommends, for the sports medicine community to consider, in the case of pivoting, contact and competitive sports, that the injured leg should be $\geq 100 \%$ of the non-injured leg in terms of both knee extensor and knee flexor strength and also $\geq 90 \%$ in terms of two maximum hop tests (such as the vertical jump and the hop for distance), as well as one hop test demanding endurable hop capacity (such as the triple jump, stair hop or side hop test). For non-pivoting, non-contact and recreational sports, $\geq 90 \%$ is recommended for both strength tests and $\geq 90 \%$ for hop performance in one of the hop tests [13].

\section{Future challenge}

In order to find better criteria for a successful and safe return to sport, more evidence-based studies are needed. Validated evaluation tools for muscle function and motor control, as well as patients' own experiences, are needed. During the last 10 years, several validated measures have been presented and should be put into clinical practice for all patients. There is also a need for valid evaluation instruments tailored for different sports and injuries. Finally, we should not look for one ultimate test but instead several tests for various aspects of muscle function, together with self-reported outcome measures evaluating various relevant dimensions important for a successful and safe return to sport after injury.

\section{References}

1. Ageberg E, Thomee R, Neeter C, Silbernagel KG, Roos EM (2008) Muscle strength and functional performance in patients with anterior cruciate ligament injury treated with training and surgical reconstruction or training only: a two to five-year followup. Arthritis Rheum 59(12):1773-1779

2. Ardern CL, Webster KE, Taylor NF, Feller JA (2010) Return to the preinjury level of competitive sport after anterior cruciate ligament reconstruction surgery: two-thirds of patients have not returned by 12 months after surgery. Am J Sports Med. doi: $10.1177 / 0363546510384798$

3. Ardern CL, Webster KE, Taylor NF, Feller JA (2011) Return to sport following anterior cruciate ligament reconstruction surgery: a systematic review and meta-analysis of the state of play. Br J Sports Med. doi:10.1136/bjsm.2010.076364

4. Augustsson J, Thomee R, Karlsson J (2004) Ability of a new hop test to determine functional deficits after anterior cruciate ligament reconstruction. Knee Surg Sports Traumatol Arthrosc 12(5):350-356. doi:10.1007/s00167-004-0518-4

5. Creighton DW, Shrier I, Shultz R, Meeuwisse WH, Matheson GO (2010) Return-to-play in sport: a decision-based model. Clin J Sport Med 20(5):379-385 
6. Fuller CW, Ekstrand J, Junge A, Andersen TE, Bahr R, Dvorak J, Hagglund M, McCrory P, Meeuwisse WH (2006) Consensus statement on injury definitions and data collection procedures in studies of football (soccer) injuries. Br J Sports Med 40(3):193-201

7. Gustavsson A, Neeter C, Thomee P, Silbernagel KG, Augustsson J, Thomee R, Karlsson J (2006) A test battery for evaluating hop performance in patients with an ACL injury and patients who have undergone ACL reconstruction. Knee Surg Sports Traumatol Arthrosc 14(8):778-788

8. Neeter C, Gustavsson A, Thomee P, Augustsson J, Thomee R, Karlsson J (2006) Development of a strength test battery for evaluating leg muscle power after anterior cruciate ligament injury and reconstruction. Knee Surg Sports Traumatol Arthrosc 14(6):571-580

9. Neuman P, Kostogiannis I, Friden T, Roos H, Dahlberg LE, Englund M (2009) Patellofemoral osteoarthritis 15 years after anterior cruciate ligament injury-a prospective cohort study. Osteoarthritis Cartilage 17(3):284-290

10. Oiestad BE, Holm I, Engebretsen L, Risberg MA (2011) The association between radiographic knee osteoarthritis and knee symptoms, function and quality of life 10-15 years after anterior cruciate ligament reconstruction. Br J Sports Med 45(7):583-588

11. Oiestad BE, Holm I, Gunderson R, Myklebust G, Risberg MA (2010) Quadriceps muscle weakness after anterior cruciate ligament reconstruction: a risk factor for knee osteoarthritis? Arthritis Care Res (Hoboken) 62(12):1706-1714

12. Osteras H, Augestad LB, Tondel S (1998) Isokinetic muscle strength after anterior cruciate ligament reconstruction. Scand $\mathrm{J}$ Med Sci Sports 8(5 Pt 1):279-282

13. Thomee R, Kaplan Y, Kvist J, Myklebust G, Risberg MA, Theisen D, Tsepis E, Werner S, Wondrash B, Witvrouw E (2011) Muscle strength and hop performance criteria prior to return to sports after ACL reconstruction. Knee Surg Sports Traumatol Arthrosc. doi:10.1007/s00167-011-1669-8

14. Wernbom M, Augustsson J, Thomee R (2007) The influence of frequency, intensity, volume and mode of strength training on whole muscle cross-sectional area in humans. Sports Med 37(3):225-264 